\title{
ФИЛОСОФИЯ
}

DOI: https://doi.org/10.15688/lp.jvolsu.2019.2.1

UDC $11 / 12$

LBC 87.12

\section{THEISTIC PSYCHOLOGY \\ AS A METHODOLOGICAL PRINCIPLE OF THE STUDY OF RELIGIOUS EXPERIENCE}

\author{
Svetlana B. Tokareva \\ Volgograd State University, Volgograd, Russian Federation \\ Vyacheslav G. Patrin \\ Tsaritsyn Orthodox Christian University, Volgograd, Russian Federation
}

\begin{abstract}
The article investigates the genesis of psychologism as a methodological basis for the study of religious experience. The authors show that the first experience of consistent applying psychologism for the purpose of radical criticism of religion was carried out by $\mathrm{D}$. Hume, who reduced the religious experience to the emotional and mental nature of man. As a result, in the philosophy of Hume, the sphere of religious experiences was completely desacralized and the concepts making up the core of spiritual and religious-ethical life of man, such as "personality", "spiritual substance", "mystical experience" were declared meaningless. In the research of F. Schleiermacher the principle of psychology was used to identify the grounds of religiosity. According to Schleiermacher, the sacred is rooted in the very nature of man in the form of original, undifferentiated "religious feeling." The type of psychologism developed by Schleiermacher is theistic because it comes from the recognition of the ontological nature of the divine spark, which is initially presented in religious experience and is not brought into it by faith, a specific creed or metaphysics. According to Schleiermacher, it is not the higher mental functions and rational consciousness that are responsible for the feeling of belonging to God, but the prethought experience together with the psychosomatic structures that provide it. Thus, theistic psychology finds the primary elements of religiosity, components creating precognitive content experienced by the human sense of the sacred beyond the usual manifestations of religion, namely faith, thinking and behavior. Later, psychologism was criticized by representatives of phenomenology, who argued that mental phenomena can be recorded as a direct evidence beyond self-consciousness. This led to the formation within the phenomenology of religion of a new kind of psychologism - transcendental psychologism, representatives of which consider religious feeling 2 as a unity of transcendental (categorical scheme of "the sacred") and psychological (religious experience as a ㄱ. mental phenomenon). The significance of theistic psychologism as a methodology for the analysis of religious $\leftarrow$ experience lies in the fact that it, firstly, served as the basis for the formation of the phenomenology of religion as the leading direction of the study of religious experience and, secondly, opened the possibility of studying the universal psychosomatic basis of religious feeling. This basis can be distinguished by comparison and comparative analysis of descriptions obtained as a result of conscious self-observation of personal spiritual experience of representatives of different religions and spiritual practices.
\end{abstract}

Key words: religion, religious background, religious experience, principle of psychologism, theistic psychologism, psychology of religion, phenomenology of religion. 
УДК $11 / 12$

ББК 87.12

\title{
ТЕИСТИЧЕСКИЙ ПСИХОЛОГИЗМ КАК МЕТОДОЛОГИЧЕСКИЙ ПРИНЦИП ИССЛЕДОВАНИЯ РЕЛИГИОЗНОГО ОПЫТА
}

\author{
Светлана Борисовна Токарева \\ Волгоградский государственный университет, г. Волгоград, Российская Федерация \\ Вячеслав Геннадьевич Патрин \\ Царицынский православный университет, г. Волгоград, Российская Федерация
}

\begin{abstract}
Аннотация. В статье исследуется генезис психологизма в качестве методологической основы изучения религиозного опыта. Показано, что первый опыт последовательного применения психологизма с целью радикальной критики религии был осуществлен Д. Юмом, редуцировавшим религиозный опыт к эмоциональнопсихической природе человека. В результате в философии Юма сфера религиозных переживаний оказалась полностью десакрализованной, а понятия «личность», «духовная субстанция», «мистический опыт», составляющие ядро духовной и религиозно-этической жизни человека, были объявлены бессодержательными. В исследованиях Ф. Шлейермахера принцип психологизма использовался для выявления оснований религиозности. Согласно его учениям сакральное укоренено в самой природе человека в виде изначального, недифференцированного «религиозного чувства». Разработанный философом вид психологизма является теистическим, поскольку он исходит из признания онтологического характера божественного начала, которое изначально присутствует в религиозном опыте, а не привносится в него верой, конкретным вероучением или метафизикой. По Шлейермахеру за чувство причастности к Богу отвечают не высшие психические функции и рациональное сознание, а предваряющее мысль переживание вместе с обеспечивающими его психосоматическими структурами. Таким образом, теистический психологизм обнаруживает за привычными проявлениями религии - верой, образом мыслей и правилами поведения - первичные элементы религиозности, составляющие предкогнитивное содержание переживаемого человеком чувства сакрального. В дальнейшем психологизм подвергся критике со стороны представителей феноменологии, утверждавших, что психические феномены могут быть зафиксированы в качестве непосредственных очевидностей за пределами самосознания. Это привело к оформлению в рамках феноменологии религии новой разновидности психологизма - трансцендентального психологизма, представители которого рассматривают религиозное чувство как единство трансцендентального (категориальной схемы «священного») и психологического (религиозного переживания как психического феномена). Значение теистического психологизма в качестве методологии анализа религиозного опыта заключается в том, что он, во-первых, послужил основой формирования феноменологии религии как ведущего направления исследования религиозного опыта и, во-вторых, открыл возможность изучения универсальной психосоматической основы религиозного чувства. Эта основа может быть выделена путем сопоставления и сравнительного анализа описаний, полученных в результате сознательного самонаблюдения за личным духовным опытом представителей различных религий и духовных практик.

Ключевые слова: религия, религиозный опыт, религиозное переживание, принцип психологизма, теистический психологизм, психология религии, феноменология религии.
\end{abstract}

Как форма внутреннего опыта религиозный опыт представляет собой непрерывный поток переживаний. Специфика его заключается в уникальности и глубокой укорененности во внутреннем мире личности. Особую значимость переживаемый духовный опыт имеет в авраамистических религиях. С одной стороны, он не считается полностью закрытым благодаря проявлению во внешних формах (объективации), которое делает возможным, во-первых, различение субъектом в непрерывности переживаний собственных желаний, чувств, состояний в качестве отдельных «предметностей» [Трунов 2010, 71]; во-вторых, осознание субъектом своих переживаний, «имение их в качестве объекта (раздражителя для других переживаний)» [Выготский 1996, 36]. Благодаря процедурам различения и осоз- 
нания религиозный опыт, сохраняя сугубо индивидуальный, субъективный характер, не остается абсолютно неизрекаемым, но может быть выражен языковыми средствами и, следовательно, доступен для трансляции, контроля и познания. С другой стороны, религиозный опыт всегда остается глубоко личностным, нетехнологичным в смысле невозможности его искусственно воспроизвести и перепроверить. Эта двойственность ставит под сомнение адекватность понимания духовного опыта и духовных практик и придает особую значимость выбору парадигмы их теоретического анализа, который определяется наряду с убеждениями и мировоззренческими установками исследователя его личной религиозностью (или ее отсутствием). Вне зависимости от того, признается ли наличие у познающего субъекта личного религиозного опыта фактором искажения реальности и препятствием для непредвзятого изучения религиозной жизни или, напротив, рассматривается как необходимое условие адекватного понимания религиозных феноменов, - результат познания будет имманентен той системе миропонимания, в которой рождаются авторский замысел и авторские интерпретации.

В исследовании религиозного опыта сложились две основные традиции. Первая традиция признает осмысленность религиозной жизни на всех ступенях ее развития, поэтому ее сторонники считают невозможным укоренять религиозный опыт в предкогнитивном переживании или чувстве. Так, Гегель относит чувства к сфере субъективного и случайного бытия, тогда как смысл религиозной жизни открывается через самопознание духа [Гегель 1976, 307-308]. С.Н. Булгаков видит роль переживаний в том, что они сопровождают религиозную жизнь, однако не определяют ее содержания [Булгаков 1994, 41]; последнее обретается через приобщение к конфессионально-теологически-философской интерпретации или традиции.

Сторонники второй традиции, напротив, выводят религиозность из некоторого мистического в своей основе чувства, по отношению к которому осознание является вторичным шагом, не способным изменить изначально содержащийся в религиозном переживании сверхличный предкогнитивный смысл и пото- му не привносящим в него чего-то радикально нового [Василенко 2006, 29]. Предполагается, что все люди обладают потенциальной возможностью пережить порождаемые исходным религиозным чувством состояния, сообщения о которых составляют предмет эмоционального (предкогнитивного) познания [Baсиленко 2006, 29]. Неизбежная непроясненность исходного мистического переживания преодолевается благодаря последующему приобщению субъекта к конкретной религиозной системе, содержание которой образует интерсубъективную основу для интерпретации и трансляции религиозного опыта.

Нетрудно видеть, что вторая позиция, ориентирующая исследователя на анализ личностных переживаний, в методологическом отношении тяготеет к психологизму. В качестве самостоятельного методологического принципа психологизм оформился и получил широкое распространение в эпоху утверждения в философии и науке эмпиризма субъективистского толка. Везде, где содержание познания ставилось в зависимость от субъекта опыта, психологизм претендовал на статус универсальной методологии, а психологические законы объявлялись инвариантными и не нуждающимися при объяснении феноменов в дополнительных теоретических конструкциях.

Редуцирование объясняемых феноменов к характеристикам субъекта («естественной природе», антропологическим свойствам, индивидуальным особенностям, личностным склонностям, потребностям, мотивам, фактам биографии и т. д.) представляет собой самую простую и раннюю форму психологизма как объяснительного принципа - редукционистский психологизм, который нашел применение при изучении сферы внутреннего опыта в целом и религиозной жизни в частности.

Редукционистские интерпретации религиозного опыта появились в эпоху Просвещения и стали частью стремительной десакрализации истории, в ходе которой «свой смысл теряют культы и обряды, традиции и мифы, древние заветы и уходящие вглубь веков предания, духовный опыт и религиозное созерцание, интуиция бытия и вкус Священного» [Дугин 2004, 270]. В результате из истории вымываются метаисторические смыслы, а события мыслятся как определенные едиными 
психологическими законами. Происхождение, сущность и многообразие религии объясняются в эволюционном ключе: ее развитые формы рассматривают как продукт развития примитивных форм религиозного опыта - прафеноменов, которые, в свою очередь, выводятся из особенностей психической жизни людей.

В исследованиях религии и религиозного опыта редукционистский психологизм получил «прописку» благодаря трудам Д. Юма. Его эмпиризм в полной мере соответствует общей характеристике этого течения как теоретического основания десакрализации мира: «Сакральная интуиция бытия, мира, проникновение в его священное измерение, переживание "божественного присутствия" - все это отбрасывается эмпириками как предрассудки, фальсифицирующие картину наблюдений внешней реальности» [Дугин 2004, 270]. Стремясь представить религиозный опыт как целиком имманентный, Юм искал его корни в эмоционально-психической природе людей. В качестве причины религиозных представлений и практики регулярных обращений людей к Богу он полагал особые психические состояния, обусловленные страхом и неудовлетворенностью жизнью; в качестве психологического механизма - фантазию, дающую иллюзию достижения счастья и преодоления «тревожной заботы о собственной судьбе» [Юм 1965, 378, 325, 429]; в качестве основы нравственного поведения - чувство симпатии, которую понимал не в значении благорасположения к другому или сочувствия, а в значении, передаваемом в современной науке нейтральным термином «эмпатия» - естественной способности человека «воспринимать душевные состояния других людей, испытывать их влияние, захватываться ими» [Апресян $2012,76]$. Таким образом, в структуре религиозного опыта не оставалось ничего мистического, и он оказывался полностью десакрализованным.

Необходимо принять во внимание, что целью исследования религии у Юма являлась ее радикальная критика. В поисках теоретических оснований критики религии он пришел к признанию бессодержательности целого ряда понятий, составляющих ядро духовной и религиозно-этической жизни человека: «личность», «духовная субстанция», «субстанци- альное Я», «спиритуалистический опыт». Отрицание тайны в человеке и в мире, признание иллюзорности представлений о Боге, духе, духовной субстанции составляли убеждения Юма. Однако отказ от личности дался ему гораздо сложнее; ради того, чтобы сорвать с человеческой жизни мистическое покрывало, Юм пожертвовал и личностью, редуцировав ее к «пучку ассоциаций» и тем самым исключив наличие у человека каких-либо «религиозных потребностей».

Представить религиозный опыт как без остатка имманентный - Юму не удалось. Его взгляды на религию характеризуются двойственностью. С одной стороны, отвечая на излюбленный вопрос метафизики и богословия: «Инициирован ли религиозный опыт трансцендентным (Богом)?», - Юм отрицает существование сверхъестественного, объявляя представления о нем плодом человеческой фантазии. С другой стороны, в своем учении о причинности он допускает, что конечная (верховная) причина порядка в мироздании может оказаться сверхъестественной и разумной.

Утвердив психологизм в качестве самодостаточной исследовательской стратегии, Юм положил начало традиции признания универсального характера психологических объяснений. Утверждение, что объяснительные гипотезы должны черпаться из эмпирических данных о психологических особенностях субъекта опыта (описываемых при помощи понятийного аппарата ассоциативной психологии), по сути лишает другие науки их собственного предмета и превращает их в прикладную психологию. Таким образом, редукционистский психологизм утверждается как радикальный методологический принцип, претендующий на подчинение себе всех других наук.

Последовательно проведенный редукционистский психологизм исключает любые вопросы о существовании и сущности трансцендентного как ненаучные. В рамках этой методологической позиции полагается, что религиозный опыт является всецело субъективным, а составляющие его чувства и представления не имеют за собой никакого реального объекта. Именно поэтому, во-первых, в центре внимания ученого здесь оказывается ис- 
следование психического мира изолированно взятой личности (биография; эмпирический опыт отдельного субъекта; анализ непосредственных данных сознания и т. п.), а в качестве основных методов исследования выступают самонаблюдение и интроспекция, что усиливает субъективность результатов [Coрина web]. Во-вторых, предполагается, что чувства и переживания, составляющие религиозный опыт, подчиняются законам ассоциативной психологии, которые являются инвариантными, применимыми для характеристики людей вне зависимости от эпох и социально-экономических условий их жизни. В качестве общего знаменателя для получения выводов о духовных состояниях выступает субъект как таковой, носитель некоторой «антропологической природы», взятый в отрыве от социально-исторических факторов. В этом случае редукционистский психологизм оказывается крайней формой натурализма, который даже институциональные характеристики религии выводит из «человеческой природы».

Приемы редукционистского психологизма широко использовались для изучения духовной жизни психологами, антропологами и социологами Альфредом Леманом, Уильямом Джеймсом, Марселем Моссом. А. Леман экспериментально доказал зависимость специфических черт восприятия магического мышления - предубежденности и иллюзорности от психологических эффектов преднастройки (ожидания) [Леман (сост.) 2002]. М. Мосс, обобщая результаты исследования магии как ранней формы приобщения к сверхъестественному и основы мистической жизни человека, указал на общую гипотезу, согласно которой магия представляет собой «первый этап психической эволюции человека», «первоначальную форму человеческого мышления», поскольку «человек поначалу не умел думать иначе, кроме как в терминах магии» [Мосс $2000,108]$. У. Джеймс предложил психологическое решение вопроса об источнике изначального отношения человека к духовной реальности. Опираясь на анализ многочисленных свидетельств религиозных людей, он пришел к выводу о том, что именно подсознательная жизнь с ее порывами, стремлениями и чаяниями постепенно подготовляет в человеке интуицию, благодаря которой что-то в нем «знает с полной достоверностью, что она ближе к истине, чем самые точные рассуждения, направленные против нее» [Джеймс 1993, 64]. При этом Джеймс подчеркивает, что с позиций психологии дело и не может выглядеть иначе: психологии негде искать источник сверхъестественного откровения, кроме как в подсознании. Джеймс полагает религию «одним из спасительных вторжений подсознательного “Я” "), источник интуиций которого «лежит в нашей природе, хотя и помещается гораздо глубже той шумно проявляющейся в словах поверхности, которой живет рационализм» [Джеймс 1993, 64].

Однако не все сторонники психологизма исключали из религиозного переживания мистическую составляющую. Развитие альтернативной позиции в трудах Ф. Шлейермахера свидетельствует о дифференциации форм психологизма как методологического принципа. В структуре внутреннего мира человека Шлейермахер выделил религиозное чувство, которое переживается как интуиция и внутреннее созерцание бесконечного и вечного и не сводимо к эмоциям и настроениям [Шлейермахер 1994]. Даже однократное переживание этого чувства навсегда закрепляет в сознании человека самоочевидность связанного с ним опыта.

В качестве мистической первоосновы жизни религиозное чувство не тождественно психологическим терминам «чувство» и «переживание». Во-первых, чувство причастности к Богу является духовнылм, экзистенциальным и осмысленным, поскольку сверхъестественное, мистическое начало присутствует в нем априори, а не привносится верой, мифом и тем более поздними культурными феноменами - вероучением и метафизикой. Вовторых, в нем неразличимы объективное и субъективное, а потому оно остается за границей различия истинного и ложного [Шлейермахер 1994, 21]. По этой причине религиозное сознание не может рассматриваться как искажающее реальность и оттого не способное привести к истине. Просто через чувство человеку даны особые истины, отличные от данных мышлению в рамках субъект-объектной дихотомии. По мнению С.Л. Франка, в своем учении о религиозном чувстве Шлейермахер предвосхитил явление «эмоциональ- 
ного знания» [Франк 1994, 19]. Применительно к «эмоциональному знанию» (и религиозному переживанию как его разновидности) затруднены или даже недоступны теоретическое осмысление и оценка; на этом основании наука полагает такое знание чем-то абсолютно субъективным, иллюзорным. Однако из того факта, что эмоциональное знание не является общезначимым, не следует, что у человека нет способов его фиксации, воспроизведения, интерпретации и трансляции.

Религиозное чувство - это психический феномен, а психическим феноменам, согласно Ф. Брентано, придает определенность особое, внутреннее восприятие, сообщающее им, с одной стороны, непосредственную и безошибочную (не логическую) очевидность; с другой - осознанность, выступающую основой повторяемости психических феноменов, их способности удерживаться в памяти (в том числе культурной) и транслироваться в традиции. Благодаря тому что очевидность внутреннего восприятия не нуждается в доказательствах и подтверждениях, религиозное переживание, будучи теоретически недоказуемым, представляет собой субъективно достоверное знание [Франк 1994, 21].

В религиозном чувстве слиты воедино обычно противопоставляемые наукой и философией объективное и субъективное, идеал и реальный факт. Поэтому утверждение о том, что религиозное переживание является исключительно субъективным, нуждается в переосмыслении. В рамках внутреннего восприятия объективизм и субъективизм имеют иную трактовку, не совпадающую с научной. Субъективизм, характерный для религиозного чувства, проявляется в степени развитости его у личности. Таким образом, Шлейермахер использует субъективизм в качестве методологии проникновения во внугренний мир личности с целью определения характера ее духовного развития. Соответственно, пагубным для познания является не сам по себе субъективизм, а неразвитость внутреннего мира личности, связанная со скудностью религиозного чувства.

Сосредоточившись на внутренней стороне жизни, Шлейермахер не ставит задачей избежать субъективизма и психологизма, но меняет их форму за счет признания сакраль- ного, мистического характера исходного религиозного чувства, в результате чего психологизм оказывается теистическим. Несостоятельность трактовки религиозного сознания как искажающего реальность и оттого не способного привести к истине признается не согласно рациональным рассуждениям, а на основании признания предкогнитивного смыслового содержания религиозного переживания, идущего «от Бога». Ни оно само, ни опирающийся на него религиозный опыт не зависят от психологической веры в трансцендентное: все высшие психические функции подключаются позднее, по мере дифференциации духовной жизни и усложнения религиозных переживаний. В дальнейшем поэтическая идеализация и теоретизация уводят человеческий дух еще дальше от исходного «чистого» религиозного чувства человека - в мир философско-теологических интерпретаций и художественного вымысла.

Утверждаемая теистическим психологизмом субстанциальность религиозного чувства как особого жизненного начала позволяет Шлейермахеру сделать важный вывод о возможности для личности поддерживать религиозный опыт даже в чуждой и враждебной ему десакрализованной среде. В силу субстанциальности религиозного чувства оно не зависит от морали, не нуждается в опоре на догматы и теорию, но само является общей исходной основой для мистики, философии, науки и поэзии. При этом религиозное сознание интуитивно чувствует границы между этими сферами и иерархию связанных с ними духовных практик и не допускает отождествления религии с онтологически вторичными по отношению к ней теоретическими и художественными формами.

Для современного человека привычно воспринимать религию как веру, образ мыслей и совокупность правил поведения. Использование теистического психологизма позволяет за этими очевидными составляющими религии обнаружить первичные элементы религиозности, которые не даны в нашем непосредственном опыте. Однако для их дальнейшего изучения необходимо сместить фокус рассмотрения, по-особому настроить «оптику» нашего видения. Этот шаг был сделан представителями феноменологического подхода Ф. Брентано и 
Э. Гуссерлем. Разработанный ими метод «внутреннего восприятия» («внутреннего сознания») позволяет фиксировать психические феномены в качестве непосредственных очевидностей до формирования самосознания и за его пределами. Этот подход послужил импульсом для появления нового направления - феноменологии религии, представители которогоМ. Шелер, Я.Ф. Фриз, М. Элиаде, Р. Отто, Г. ван дер Леув и др. - по-новому использовали эвристические возможности психологизма при решении проблемы «изначально религиозного».

Речь идет о переосмыслении соотношения между основными составляющими религии: чувством, верой и убеждением. Так, Р. Отто фиксирует «изначально религиозное» категорией «священное», понимая ее, вслед за Я.Ф. Фризом, по-кантиански - как «схему», задающую благодаря наличию у человека веры и религиозного убеждения «позитивное знание вечного» [Отто 2008]. Однако у веры есть и другая производная - религиозно-эстетическое предчувствие прекрасного и возвышенного. Таким образом, духовная сфера человека представляет собой область рационально-эмоционального единства идей и эстетически-религиозного чувства, доступную психологическому самоанализу. Религиозное сознание конституируется через эстетическирелигиозное «предчувствие» святости как таинственной силы и переживаемого в отношении ее смирения.

Вариант психологизма Фриза и Отто можно обозначить как трансиендентальный. Его исходной точкой является «психологизация формального априори», в результате которой в религиозном чувстве становятся неразличимы трансцендентальное и психологическое: религиозное чувство является эмпирически данным психическим феноменом и одновременно входит в категорию священного (которая является формальным условием остальных религиозных феноменов). Подобное соединение в категории «священное» трансцендентального и эмпирического, помещение «чистого» априорного понятия в сознание в качестве первичного психического элемента является отступлением от классической феноменологии. Получается, что категориальная «схема» священного, включающая религиозное переживание, существует вне всех остальных категорий и выступает источником категоризации других религиозных феноменов.

Во всех случаях, когда интерес к внутреннему миру человека заставляет исследователя обратиться к его жизненным обстоятельствам как принципам его самоопределения, психологизм берет на себя роль ведущего методологического принципа. При этом в результате дифференциации психологизма как общего методологического принципа оформляются и получают развитие специализированные формы психологизма, используемые затем в различных парадигмах, научных дисциплинах и областях культуры [Сорина web]. Исследование показало, что эвристическая эффективность конкретных форм психологизма относительна и зависит от исследовательской задачи.

Выводы. Применительно к изучению религиозного опыта общим для всех форм психологизма является, во-первых, редукция этого опыта к субъективным переживаниям; вовторых, выведение потребности в сакральном из антропологической природы, отождествляемой с психической жизнью; в-третьих, признание допустимости анализа любых феноменов духовной жизни, в том числе связанных с переживанием сакрального, эмпирическими психологическими методами. Редукционистский психологизм определяет религиозный опыт как происходящий в субъективном мире психический процесс и предполагает возможность сведения религиозного поведения человека к обусловливающим его психологическим мотивам. При этом используемые при изучении религиозного опыта процедуры эмпирического доказательства призваны исключить влияние личного жизненного опыта исследователя на интерпретацию полученного результата.

Теистический психологизм появляется как альтернатива универсальной редукционистской версии психологизма и представляет собой специфическую, «высоко дифференцированную» форму данного методологического принципа. Признавая недостаточность психологического факта веры в существование трансцендентного в качестве основания религиозного опыта, теистический психологизм отрицает правомерность редукции религиозного переживания к общему «психологическому переживанию». При таком подходе ре- 
лигиозность не связывается с вероучением, а потому даже в секулярные эпохи религиозный опыт не может быть полностью десакрализован. Первичный духовный смысл запечатлен в изначальном импульсе духовного переживания в силу присутствия в нем сверхсубъективного, мистического начала. Таким образом, позиция теистического психологизма характеризуется известной двойственностью: когда исследователь религии утверждает первичность «чистого» религиозного переживания, не зависящего от философско-теологической интерпретации, он выступает как психологист; но если он одновременно признает наличие в религиозном чувстве предкогнитивного смыслового содержания, идущего «от Бога», он выражает теистическое мироощущение, позицию верующего человека.

Значение теистического психологизма в качестве методологии анализа религиозного опыта заключается в том, что он, во-первых, послужил основой формирования феноменологии религии как ведущего направления современного религиоведения и, во-вторых, открывает возможность изучения универсальной психосоматической основы религиозного чувства. Эта основа может быть выделена путем сопоставления и сравнительного анализа описаний, полученных в результате сознательного самонаблюдения за личным духовным опытом представителей различных религий и духовных практик, что является предметом дальнейших исследований.

\section{СПИСОК ЛИТЕРАТУРЫ}

Апресян 2012 - Апресян Р.Г. Смысл морали в этике Дэвида Юма // Этическая мысль. Вып. 12. М.: ИФ РАН, 2012. С. 72-103.

Булгаков 1994 - Булгаков С.Н. Свет Невечерний. Созерцания и умозрения. М.: Республика, 1994.

Василенко 2006 - Василенко Л.И. О познавательном значении религиозного опыта // Вестник ПСТГУ (Вестник Православного Свято-Тихоновского гуманитарного университета). Серия I: Богословие. Философия. Религиоведение. 2006. Вып. I: 16. С. 23-44.

Выготский 1996 - Выготский Л.С. Сознание как проблема психологии поведения // Психология развития как феномен культуры: избранные психологические труды. М.: Институт практической психологии; Воронеж: НПО «МОДЭК», 1996.

Гегель 1976 - Гегель Г.В.Ф. Философия религии. В 2 т. Т. 1. М.: Мысль, 1976.

Джеймс 1993 - Джеймс У. Многообразие религиозного опыта. М.: Наука, 1993.

Дугин 2004 - Дугин А.С. Философия политики. М.: Арктогея, 2004.

Леман (сост.) 2002 - Леман А. (сост). История Магии и суеверий: от древности до наших дней. М.: Эксмо, 2002.

Mocc 2000 - Мосс M. Социальные функции священного. Избранные произведения. СПб.: Евразия, 2000.

Отто 2008 - Отто Р. Священное. СПб.: Изд-во СПбГУ, 2008.

Сорина web - Сорина Г.В. Логико-культурная доминанта. Очерки истории психологизма и антипсихологизма в культуре. М.: Прометей, 1993 // http://cyberleninka.ru/article/n/ metodologiya-logiko-kulturnoy-dominantypsihologizm-antipsihologizm-subekt.

Трунов 2010 - Трунов Д.Г. Объективация психического опыта // Вестник Пермского университета. 2010. Вып. 3 (3). С. 71-81.

Франк 1994 - Франк С.Л. Предисловие // Шлейермахер $\Phi$. Речи о религии к образованным людям ее презирающим. Монологи: пер. с нем. и предисл. С.Л. Франка. СПб.: Алетейя, 1994.

Шлейермахер 1994 - Шлейермахер Ф. Речи о религии к образованным людям ее презирающим. Монологи: пер. с нем. и предисл. С.Л. Франка. СПб.: Алетейя,1994.

Юм 1965 - Юм Д. Соч. В 2 т. Т. 2. М.: Мысль, 1965.

\section{REFERENCES}

Apresyan R.G., 2012. The meaning of morality in the ethics of David Hume. Ethical Thought, Iss. 12. Moscow, IF RAN [Institute of philosophy, Russian Academy of Sciences], pp. 72-103.

Bulgakov S.N., 1994. Light Nesecery. Contemplation and speculation. Moscow, Respublika.

Vasilenko L.I., 2006. On the cognitive value of religious experience. St. Tikhon's University Review. Series 1. Theology. Philosophy. Religious Studies, Iss. 1: 16, pp. 23-44.

Vygotsky L.S., 1996. Consciousness as a problem of behavior psychology. Psychology of development as a phenomenon of culture: selected psychological works. Moscow, Institute of practical psychology; Voronezh, NPO «MODEK».

Hegel G.V.F., 1976. Philosophy of religion. In 2 vols. Vol. 1. Moscow, Mysl'. 
С.Б. Токарева, В.Г. Патрин. Теистический психологизм как методологический принцип исследования

James W., 1993. The varieties of religious experience. Moscow, Nauka.

Dugin A.S., 2004. Philosophy of politics. Moscow, Arktogeya.

Lehman A., ed., 2002. History of Magic and superstitions: from antiquity to the present day, compiled by Dr. Alfred Lehman. Moscow, Eksmo, 2002.

Moss M., 2000. Social functions of the sacred. Selected works. Saint Petersburg, Evraziya.

Otto R., 2008. Sacred. Saint Petersburg, St. Petersburg University Press.

Sorina G.V., 1993. Logical and cultural dominant. Essays on the history of psychology and antipsychologism in culture. Moscow, Prometey. URL: http:// cyberleninka.ru/article/n/metodologiya-logikokulturnoy-dominanty-psihologizm-antipsihologizmsubekt.

Trunov D.G., 2010. Objectification of mental experience. Bulletin of Perm University, Iss. 3 (3), pp. 71-81.

Frank S.L., 1994. Preface. Schleiermacher F. Speech about religion to educated people despising her. Monologues. Saint Petersburg, Aleteya.

Schleiermacher F., 1994. Speech about religion to educated people despising her. Monologues. Saint Petersburg, Aleteya.

Hume D., 1965. Essays. In 2 vols. Vol. 2. Moscow, Mysl'.

\section{Information about the Authors}

Svetlana B. Tokareva, Doctor of Sciences (Philosophy), Head of the Philosophy Department, Volgograd State University, Prosp. Universitetsky, 100, 400062 Volgograd, Russian Federation, svettok2008@yandex.ru, socphil@volsu.ru,https://orcid.org/0000-0003-4274-6444

Vyacheslav G. Patrin, Candidate of Theology, PhD (Études grecques, Sorbonne), Dean of the Theological Faculty, Tsaritsyn Orthodox Christian University, Chapaeva St., 26, 400012 Volgograd, Russian Federation, patrin.viacheslav@gmail.com, https://orcid.org/0000-0001-6376-5076

\section{Информация об авторах}

Светлана Борисовна Токарева, доктор философских наук, заведующая кафедрой философии, Волгоградский государственный университет, просп. Университетский, 100, 400062 г. Волгоград, Российская Федерация, svet-tok2008@yandex.ru, socphil@volsu.ru, https://orcid.org/0000-0003-4274-6444

Вячеслав Геннадьевич Патрин, кандидат богословия, $\mathrm{PhD}$ (Études grecques, Sorbonne), декан богословского факультета, Царицынский православный университет, ул. Чапаева, 26, 400012 г. Волгоград, Российская Федерация, patrin.viacheslav@gmail.com, https://orcid.org/0000-0001-6376-5076 